\title{
On Spatial Spillover and Industrial Agglomeration of Financial Crises to Real Economy
}

\author{
Wei Tian* ${ }^{*}$, Li Li, Yixiang Tian* \\ School of Economics and Management, University of Electronic Science and Technology of China, Chengdu, China \\ Email: "tianyx@uestc.edu.cn
}

How to cite this paper: Tian, W., Li, L. and Tian, Y.X. (2020) On Spatial Spillover and Industrial Agglomeration of Financial Crises to Real Economy. Journal of Mathematical Finance, 10, 464-482. https://doi.org/10.4236/jmf.2020.103028

Received: July 27, 2020

Accepted: August 25, 2020

Published: August 28, 2020

Copyright $\odot 2020$ by author(s) and Scientific Research Publishing Inc. This work is licensed under the Creative Commons Attribution International License (CC BY 4.0).

http://creativecommons.org/licenses/by/4.0/

\begin{abstract}
The finance sector now shows an accelerating trend of virtualization. It is rather pressing for us to enhance coordinated development of the finance market and the real economy. This paper analyzes the mixed conduction mechanism for the finance field and the real economy, and it has been a hot topic in the finance sector to capture the spatial effect and enhance the estimation precision. This paper introduces the regional spatial gravitational effects, which, together with the indicators of the financial market and the real economy, defines the broad economic metric distance and Gravitational effects Spatial Weights Matrix, constructs broad multi-dimensional economic space, and builds multi-variate Spatial-FIAPARCH-DCC models and Spatial SUR contagion models, to explore the impact of the financial crisis on different regions and different real economy sectors. Our research shows that the broad multi-dimensional space has remarkable advantages in the spatial effect between the financial market and the real economy, and there is asymmetric relation between the extent to which the real economy suffers and the degree to which the financial market suffers. The effects of the financial crisis on the real economy show remarkable sectoral industrial agglomeration and hierarchy.
\end{abstract}

\section{Keywords}

Spatial Econometrics, Financial Contagion, Spatial SUR, Spatial

FIAPARCH-DCC

\section{Introduction}

International financial integration has remarkably enhanced the spatial effects ${ }^{*}$ First author. 
between all economies, speeding up the global investment transfer and risk contagion, helping distribute risks and adding to the global spreading of the financial crisis. The American subprime mortgage crisis and the European Debt Crisis breaking out in succession after 2007 in particular deteriorated the financial market, and constituted tremendous impact on the real economy, ushering in multi-dimensional mixed conduction between the financial market and various sectors of the real economy. The contagious properties of the real economy lead to spatially linked response of returns on assets in different regions and different sectors. This spatial spillover effect of assets brings about potential returns on investments, and demands higher requirements for assets management. The Chinese financial reform is getting deeper, and the capital projects more open. To curb the increasing trend of virtualization in the financial sector, we have researched into the dynamic evolution mechanism of the crisis impact paths from the multi-dimensional spatial perspective of integrating the real economy and the financial market, helping to form effective risk prevention and disposal mechanism and maintain economic stability after the marketization and internationalization of the financial sector.

The financial contagion mechanism and the dynamic evolution mechanism path has been a hot topic for research at home and abroad; only by accurately depicting the conduction mechanism of the financial crisis can we make relevant policies to have effective control [1]. Rodriguez (2007) proposed to apply the Copula function to measuring the financial contagion, using the correlation theory to empirically analyze the conduction process of the Asian Financial Crisis and the Mexican Financial Crisis [2]. On this basis, Cheng et al. (2012) proposed that the Copula contagious index (or CCI for short) works better to reflect the non-linear correlation between the financial markets than the convention linear correlation coefficient does [3]; Asgharian and Nossman (2011) made use of the earning rate and the jumping volatility to establish a Stochastic volatility model and study the risk spillover effect between the European and American financial markets, and identify the conduction mechanism between the markets [4]. Chudik and Fratzscher (2012) made use of the global VAR methods to investigate the conduction process of the liquidity shock and risk shock between the financial markets around the globe during the American subprime mortgage crisis and the European Debt Crisis. Some empirical study shows that the different shock paths are determined by the sovereign credit rating, financial risks and the system [5]. Tian Yixiang et al. (2013) made use of the dynamic models of international panel data to empirically analyze the different impacts of the changing sovereign credit rating on the stocks, securities and credit markets [6]; Oh (2013) analyzed the dynamic spreading evolution of the liquidity crisis from the perspective of the creditor's investment behaviors [7]; Mckibbin et al. (2014) believed that the risk contagion channel involves the financial higher moments of asset return and the change of the average return structure of the cross capital markets [8]. The above scholars have made use of different financial contagion mechanism to do research into the research object of the general stock index of 
the financial markets of various economies.

Recent years, some researchers have found the cross-sector contagious path of the real economy has played an even more important role in the financial contagion process relative to the general stock index (Cavaglia et al., 2000 [9]; Phylajtus and Xia, 2006 [10]), which the cross-sector conduction path plays a more and more important role in the contagion process of the global financial crisis. Phylaktis and Xia (2009) [11] have studied assets pricing, and found that the existing cross-sector mixing contagion has added to the risky impact of the financial crisis, but it has also brought about potential returns to the investors; Horta et al. (2010) has made use of the Copula function to investigate the general stock indexes of 4 European economies and the stock indexes of two sectors (finance and industry), and his findings show that the financial contagion has impact on all regions and sectors [12]. Bekaert et al. (2011) have empirical analysis of the stock assets combination of 415 different trades from 55 nations, and their findings show that the financial contagion mainly takes place across different sectors in the same region [13]. Baur (2012) investigates the impact of the American subprime crisis across the global financial market and the real economy, and he has found that during the process of diversified investment combination, no nation or sector stays immune, and healthcare, science and technology, telecommunications and other sectors see smaller impact [14]. Kenourgios and Dimitriou (2015) makes use of the FIAPARCH model to have empirical test of the impact of the economic crisis on the real economy across economies in different stages, whose findings show that the contagion mechanism works cross the financial markets of different regions and the mixed path between the financial sector and the real economy [15]. The mixed contagion across the financial market and real economy sectors has now drawn a lot attention of scholars home and abroad, but no in-depth research has been done on the sectoral agglomeration and impact path of the real economy at the sectoral levels.

With more and more remarkable significance of the spatial effect across different regions, sectors and markets, the spatial correlation of economic data shows some new multi-dimensional properties, and the conventional metering method may see errors in measurement. In this context, the spatial statistics and the spatial econometrics have emerged rapidly, and the spatial econometrics theories and applications have become a hot topic in economics. Spatial econometrics was thus recognized as the hottest research field by the Journal of Regional Sciences in 2013 [16]. Spatial econometrics now has been applied to regional economics, economic geography, environmental science, environmental criminology and other fields [17] [18] [19] and [20]. Recent years, some scholars at home and abroad started to make use of the spatial econometrics to capture the spatial effect in the financial market, and enhance its estimation precision. Kelejian et al. (2006) has researched into the financial impact conduction mechanism across new economies with spatial econometrics [21]; Inci et al. (2011) has researched into and confirmed the financial risk spreading of the American stock spot market to other countries [22]. Cheng et al. (2012) have researched 
into the American subprime crisis, and applied the spatial econometrics models, and their findings show that the international trade channel plays less important role in financial contagion [23]. Eckel et al. (2011) have done some research whose findings show that the correlation between the returns of stocks in the financial markets is related to the geographic location [24]. Dell et al. (2013) makes use of the Spatial Econometrics method to study the spatial spillover effect of the sovereign securities markets around 24 emerging economies from 1995 to 2010, and have found that there are significant spatial spillover effects of sovereign spreads between "neighboring" economies [25]; Tam (2014) makes use of the spatial correlation to analyze the market correlation structure and impact conduction mechanism in terms of time and domain [26]. Arnold et al. (2013) built up the spatial auto-regression models for the stock market, and conduct empirical analysis with the European Stoxx 50 indexes, which shows that we can have more accurate risk prediction, combining the spatial technique and the financial market theory to build models [27]. The above literature shows that there exists spatial effect between different financial markets, and many scholars at home and abroad have started to make use of the spatial econometrics to study the risk conduction and the assets combination risk management and other financial fields.

Analyzing the above literature, we have found that these researchers on financial contagion at home and abroad have ignored the multi-dimensional spatial effect of the real economy and the financial market across the markets and regions, with no attention to investigate the spatial effect and sectoral agglomeration of the risk conduction of the financial market, as well as the spatial mixed conduction mechanism of the real economy and the financial market. Currently, the global financial sector sees an acceleration trend of virtualization, and it is rather urgent to effectively capture the multi-dimensional spatial effect between the financial market and the real economy, and realize coordinated and matched development between the two. Meanwhile, it is also necessary to explore the mixed impact effect of the financial contagion across different regions, markets and sectors. These research efforts are conducive to understanding the investors behavioral information and the risk conduction mechanism around different regions and trades, and during economic instability, they help obtain potential returns. They also provide theoretical reference for the government to make economic incentive policies.

On this basis, this paper makes use of the local spatial gravitational effects and the time-varied T-Copula function, which, together with the indicators of the financial market and the real economy, define the broad economic metric distance and Gravitational effects Spatial Weights Matrix (or GESWM for short), and construct the broad multi-dimensional economic space, to build diversified Spatial-FIAPARCH-DCC models and Spatial SUR contagion models, to explore the impact of the financial crisis on different regions and different real economy sectors against the background of the European Financial Crisis. 
The paper is arranged as follows: Section 2 introduces the research method of this paper, defining "economic distance" and "gravitational spatial weight matrix", proposing the "broad multi-dimensional economic space" and build up multi-variate Spatial-FIAPARCH_DCC models and spatial SUR contagion models. Section 3 conducts the empirical analysis, involving data selection and pre-processing, volatility dynamic conduction correlation analysis, capturing multi-dimensional spatial effect, and analyzing the shock effect of the financial contagion on different real economy sectors in different regions. Section 4 sums up the whole paper.

\section{Research Methods}

\subsection{Broad Multi-Dimensional Economic Space}

The economies around the globe are getting more and more diversified and multiple-staged, and the spatial techniques are also developing a sustained manner; all economies show multi-dimensional spatial correlation across regions, markets and sectors, and at the same time, regional difference and time delays and other factors make bring about multi-dimensional spatial heterogeneity between various economies. The global Internet finance is emerging, and most financial operators make use of electronic transactions, and the spatial definition between the financial markets have gone beyond the regional economic space in its narrow sense, and the current economic spatial theory and Spatial Econometrics method could not completely capture the multi-dimensional spatial effect in the financial market. Therefore, we first defined the broad economic metric distance and gravitational spatial weight matrix, to construct the broad multi-dimensional economic space.

\section{1) Broad economic distance measurement}

While applying the spatial econometrics to study the real economy, most scholars at home and abroad take the physical distance as the substitute for the economic distance, but in conventional sense, the indexes of physical distance cannot validly measure the "distance" between the financial markets any more, and it has become a hot topic for scholars at home and abroad to define the broad economic metric distance that satisfies the financial market. Pirinsky and Wang (2006) have done some research and found that the stock market pricing shows significant regional property thanks to regional information, similar behavioral preference and trade modes, and meanwhile the stock yield correlation decreases along with the increase of regional physical distance [28]. Eckel et al. (2011) [24] and Fernandez (2011) [29] have made use of the spatial statistics, and spatial econometrics to study the spatial correlation between various financial markets, and take the correlation coefficients of the stock indexes of all econometrics as the substitute of the economic distance. On this basis, this paper refers to the economic metric distance algorithm of Mantegna et al. (2000) [30] and Elhorst et al. (2013) [16], which, in combination with the regional physic distance and the financial market correlation index, defines the broad economic 
metric distance, and the economic metric distance between the financial market $i$ and the financial market $j$ is defined as shown by Equation (1).

$$
D_{i, j}=F\left(R_{i, j}, d_{i, j}\right)=\sqrt{1-\left|R_{i, j}\right|^{1+d_{i, j}}}, D_{i, j} \in[0,1]
$$

where $d_{i, j} \in[0,1)$, it refers to the relative physical distance between the financial market $i$ and the financial market $j$; with the longitude and latitude of the region where each financial market is located as the end coordinates, we make use of the software ArcGIS to calculate the physical distance between various financial markets, indicated by $d_{i, j}^{\prime}$, and the relative distance $d_{i, j}=d_{i, j}^{\prime} / \max \left(d_{i, j}^{\prime}\right)$; $R_{i j}$ refers to the correlation index between the financial market $i$ and the financial market $j$. Here, we make use of the important stock index logarithmic return rate of all economies to depict the prosperity of various financial markets; and the stock return rate shows non-linear partial, Lower Tail Dependence and other characteristics, and the time-varied T-Copula function can just depict this property of the stock return rate sequence accurately, so we use $R_{i, j}$ (the correlation coefficient of binary T-Copula function) to indicate the non-linear correlation between financial markets $i$ and $j$.

From Equation (1), we can obtain the following properties: 1) When $R_{i, j} \in(-1,+1)$, the economic distance $D_{i, j}$ was jointly determined by the correlation coefficient $R_{i, j}$ and the physical distance $d_{i, j}$; the bigger the $R_{i, j}$ is, and the smaller the $d_{i, j}$ is, the smaller the economic distance $D_{i, j} ; 2$ ) when the economy $i$ and the economy $j$ are absolutely irrelevant, i.e. when $R_{i, j}=0$, $d_{i, j}=1$, the economic distance $D_{i, j}$ reaches the maximum of $1 ; 3$ ) when the economy $i$ and the economy $j$ belong to the same market, i.e. $R_{i, j}=1, d_{i, j}=0$, $D_{i, j}=0$, and the economic distance reaches the minimum value of 0 . The above properties are in line with the actual spatial characteristics of the financial market, so it is rational for us to define the broad economic metric distance in combination with the regional physical distance and the correlation indexes of the financial market.

\section{2) Building the gravitational spatial weight matrix}

To research into the shock effect of the financial crisis on the real economy, we, based on the research of Vega and Elhorst (2013) [16], we make use of the above broad economic metric distance, and introduce the spatial gravitational effects of the regional economic from multi-dimensional perspective, which, together with the geographic regional weight and the real economy state weight indexes to construct the Gravitational effects Spatial Weights Matrix, or GESWM for short), indicated by $W_{g e}$. The spatial element $i$ and the spatial element $j$ have corresponding matrix elements, defined as shown by Equation (2).

$$
w_{i j}=c \cdot \frac{m_{i} m_{j}}{\exp \left(D_{i, j}\right)}
$$

where, $c$ is constant, $D_{i, j}$ refers to the broad economic metric distance between the financial market $i$ and the financial market $j$, and $m_{i}$ refers to the gravitational effect of the real economy of the $i$-th $(i=1,2, \cdots, n)$ economy. Its 
implicit economic implications show that the economy of higher investment appeal has bigger spatial impact on the "neighboring" economy. Here we would like to make use of the models and variable weight coefficient built by Liu et al. (2012) [31] to solve for the value of $m_{i}$, whose specific model is shown by Equation (3).

$$
\begin{aligned}
\ln \left(\text { Invest }_{i t}\right)= & \alpha_{i t}+\beta_{1} \ln \left(S U M_{i t}\right)+\beta_{2} \ln \left(W A G E_{i t}\right)+\beta_{3} \ln \left(\text { TELEC }_{i t}\right) \\
& +\beta_{4} \ln \left(L A N D_{i t}\right)+\varepsilon_{i t}
\end{aligned}
$$

where Invest $_{i t}$ refers to the investment appeal of the economy $i$ during $t$, whose interpreting variables are shown in Table 1.

i.e.:

$$
\begin{aligned}
m_{i t}=\ln \left(\text { Invest }_{i t}\right)= & 1.23 \ln \left(S U M_{i t}\right)-0.55 \ln \left(W A G E_{i t}\right) \\
& +0.43 \ln \left(\text { TELEC }_{i t}\right)-0.11 \ln \left(L A N D_{i t}\right)
\end{aligned}
$$

\subsection{Building Spatial Econometrics Models}

\section{1) Diversified Spatial-FIAPARCH-DCC models}

On the basis of broad multi-dimensional economic space, we have built two stages of multivariate Spatial-FIAPARCH-DCC to capture the dynamic spatial properties of the abnormal volatilitys across the financial markets in different regions, and between the financial market and the real economy.

During the first stage, we first built the univariate (1) - FIAPARCH $(1, d, 1)$ models to capture the volatility properties of each financial market. The stock yield time sequence has $r_{t}$ the AR (1) process as shown by Equation (5):

$$
(1-\mu L) r_{t}=\omega+\varepsilon_{t}, \quad t \in N, \quad \varepsilon_{t}=e_{t} \sqrt{h_{t}}
$$

where $|\omega| \in[0, \infty),|\mu|<1,\left\{e_{t}\right\}$ is independent identically distributed random variable, and $E\left(e_{t}\right)=E\left(e_{t}^{2}-1\right)=0$, the conditional variance $h_{t}=f\left(\Sigma_{t-1}\right)$, and $\Sigma_{t-1}$ is $\left\{r_{t-1}, r_{t-2}, \cdots\right\}$ the sigma-algebra generated from the sequence, i.e. we have $E\left[r_{t} \mid \Sigma_{t-1}\right]=\omega+\mu r_{t-1}, \operatorname{Var}\left[r_{t} \mid \Sigma_{t-1}\right]=h_{t}$.

At this point, we have introduced the FIAPARCH $(1, d, 1)$ models to depict the long memory property, asymmetry and dynamic heteroscedasticity of the conditional volatility of the financial market (Tse and Tsui (2002) [32], Forbes and Rigobon (2002) [33]). Specifically, they are shown by Equation (6):

$$
(1-\xi L)\left(h_{t}^{\delta / 2}-c\right)=\left[(1-\xi L)-(1-\lambda L)(1-L)^{d}\right]\left(1+\gamma S_{t}\right)\left|\varepsilon_{t}\right|^{\delta}
$$

Table 1. Variables of investment appeal interpreting.

\begin{tabular}{cccc}
\hline Variables & Variable definitions & Symbols & Weights \\
\hline Market scale & Total consumption of the economy & $S U M_{t u}$ & 1.23 \\
Labor costs & Monthly salary per labor on average & $W A G E_{t}$ & -0.55 \\
$\begin{array}{c}\text { Investment } \\
\text { technological innovations }\end{array}$ & Total R\&D input & $T E L E C_{t t}$ & 0.43 \\
Land costs & Housing prices for all nations on average & LAND $_{u t}$ & -0.11 \\
\hline
\end{tabular}


where, $c \in(0, \infty),|\xi|<1,|\lambda|<1$, and $0 \leq d \leq 1$; when $\varepsilon_{t}<0, s_{t}=1$, and when $\varepsilon_{t} \geq 0, s_{t}=0 . \gamma$ It shows the leverage factor: when $\gamma>-1, h_{t}$ is positive, and the parameters combined $(\lambda, d, \xi)$ satisfy inequality constraints (Conrad et al., 2011 [34]).

During the second stage, we find solution for the conditional variance of the single spatial element based on the first stage $h_{t}=\left[h_{i, t}\right]_{i=1, \cdots, N}$. Tse and Tsui (2002) have proposed the multivariate dynamic conditional correlation (DCC) models [32], whose specific form is shown in Equation (7):

$$
H_{t}=D_{t} C_{t} D_{t}
$$

where $D_{t}=\operatorname{diag}\left(\sqrt{h_{1, t}}, \sqrt{h_{2, t}}, \cdots, \sqrt{h_{N, t}}\right), C_{t}$ refers to the correlation matrix.

This paper builds the Spatial-DCC models under the broad multi-dimensional economic space, and supposes the volatility has spatial spillover effect. At this point, we take $h_{t}$ as time sequence, and based on Equation (2), we calculated the spatial correlation weight matrix and take it as substitute of $C_{t}$.

Therefore, multi-variate Spatial-FIAPARCH-DCC is defined as Equation (8) as shown below:

$$
B(L)\left(H_{t}^{\delta / 2}-c\right)=[B(L)-\Delta(L) \Phi(L)]\left[\left(I_{N}+\Gamma_{t}\right)\right]\left|\varepsilon_{t}\right|^{\delta}
$$

where $B(L)=\operatorname{diag}\{\xi(L)\}, \quad \xi(L)=\left[1-\xi_{i} L\right]_{i=1, \cdots, N}, \quad \Phi(L)=\left[1-\lambda_{i} L\right]_{i=1, \cdots, N}$, $c=\left[c_{i}\right]_{i=1, \cdots, N}, \Delta(L)=\operatorname{diag}\{d(L)\}, d(L)=\left[(1-L)^{d_{i}}\right]_{i=1, \cdots, N}$, $\Gamma_{t}=\operatorname{diag}\left\{\gamma \times s_{t}\right\}, \quad \gamma=\left[\lambda_{i}\right]_{i=1, \cdots, N}, \quad s_{t}=\left[s_{i, t}\right]_{i=1, \cdots, N}$.

As shown in Figure 1, the original data sequence $r_{t}$ is substituted into AR (1) - FIAPARCH $(1, D, 1)$ model, and the conditional volatility sequence $h_{t}$ of a single spatial unit is obtained. Then, it is substituted into the Spatial-DCC model to obtain the multivariate dynamic conditional volatility sequence $H_{t}$ which we need for later modeling.

\section{2) Spatial SUR contagion models}

All economies now are seeing increasingly higher correlation across regions, markets and sectors, and in the context of big data, the spatial effect is increasing, and the estimation results of conventional metering method will see variation. In this context, we combine the spatial econometrics theories and the financial contagion model, to build the Seemingly Unrelated Regression (or SUR for short) contagion models to measure the impact of the financial crisis on different regions and different real economy sectors. Its specific construction process is shown below.

Baur (2012) [14] has tested the impact of the subprime crisis on the real economy of various economies, and based on the research of Bekaert et al. (2005) [35] we have proposed the financial contagion models as shown by Equation (9).

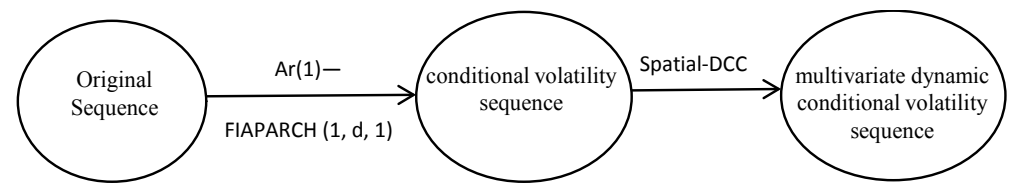

Figure 1. The establishment process of Spatial-FIAPARCH-DCC model. 


$$
R_{s, i, t}=a+b_{1} R_{F I N, m, t}+b_{2} R_{F I N, m, t} D_{t}+e_{s, i, t}
$$

where $R_{s, i, t}$ the stock logarithm yield of the economy no. is real economy $s$, $R_{F I N, m, t}$ refers to the financial sector stock logarithm yield of the financial crisis source $m ; D_{t}$ is a virtual variable, and in the time interval of samples, if the date $t$ is in the duration of the financial crisis, $D_{t}=1$, otherwise $D_{t}=0$. Therefore, the factors $b_{1}$ and $b_{2}$ respectively refer to, during the two durations of stable financial period and the financial crisis, the impact of the financial market volatility of the $m$ the economy on the economy no. is the real economy s.

To capture the spatial heterogeneities like regional difference, trade polices and time delay between relevant sectors of the real economy among various economies, we have built up the spatial SUR models to measure the spatial effect during the financial crisis conduction process and their different impacts on different industries. The spatial model form is shown by Equation (10):

$$
R_{s, i, t}=\rho W R_{s, i, t-1}+\beta_{s, i, 1} R_{F I N, m, t}+\beta_{s, i, 2} R_{F I N, m, t} \cdot D_{t}+e_{i, t}
$$

In this paper, we set, in the table of $R_{s, i, t}$, the volatility sequence of the stock logarithm yield of the economy no. is real economy sector $s$, which is solved from Equation $8 ; R_{F I N, m, t}$ refers to the volatility sequence of the stock logarithm yield of the financial sector of the economy no. $m ; D_{t}$ is a virtual variable, whose evaluation is the same to that of Equation (9); $\rho$ is the spatial correlation coefficient, which captures the spatial effect during the conduction process. $\beta_{s, i, 1}$ and $\beta_{s, i, 2}$ respectively refer to, during the stable finance period and the financial crisis, the economy $m$ having the impact on the economy no. is real economy $s$, where the $i$ evaluation can be identical to $m$, and they belong to the same economy.

\section{Empirical Study and Findings Analysis}

\subsection{Data Selection and Pre-Processing}

This paper focuses on the impact effect of the spatial spillover and shock of the financial sector crisis on the real economy during the European sovereign debt crisis. Here we chose the important stock indexes and ten major sectoral indexes of four regions-the Greece, the source of the European debt crisis, and Europe, America and China, and the 10 sectors include finance, base materials, telecommunications, industry, utilities, science and technology, energy, consumer services, consumer goods and medical and health care. All indexes make use of the daily stock log yield and local current for metering; the local metering is used for metering, so as to analyze the impact of the financial sector on other real economy sectors from the perspective of the local economy or the investors. The sampled time interval is from January 1, 2005 to December 31, 2014. The above relevant data have their source from the database-Datastream, and during the process of building the Gravitational effects Spatial Weights Matrix, the data of the macro economic index comes from the database of Wind. 
According to the classification of the evolution stages of the European Debt Crisis by the World Bank, and considering the financial crisis source-Greece and its stock index $\operatorname{AR}(1)$-FIAPARCH $(1, d, 1)$ volatility (Figure 2 ) and relevant event points (Lehman Brothers declared their bankruptcy on September 15, 2008, which had tremendous impact on Europe and Greece;), on December 8, 2009, Fitch Ratings lowered its credit evaluation of the credit rating of Greece, and the financial crisis went worse; on January 10, 2013, the European Debt Crisis slowed down and continued), we have divided the European Debt Crisis into four stages: 1) From September 15, 2008 to December 8, 2009: The financial crisis lurked, and the conditional volatility of the Greek stock index surged to a large value, then fell to normal after several months of volatility. 2) From December 8, 2009 to March 7, 2011: The financial crisis broke up and spread to other economies, and various financial market under the impact deteriorated. The conditional volatility of the Greek stock index began to rise in the shock. 3) From March 7, 2011-January 10, 2013: The financial crisis broke out, and all real economy of various economies deteriorated. The conditional volatility of the Greek stock index continued to fluctuate violently, peaked and then fell rapidly. 4) From January 11, 2013 to December 31, 2014: the financial crisis slowed down and stayed. The conditional volatility of the Greek stock index continued to slide to normal levels.

\subsection{Fluctuation Dynamic Conduction Correlation Analysis}

This section, considering the multi-dimensional effect, measures the dynamic correlation of various indexes of Greece, Europe, America and China across regions, markets and sectors during the European Debt Crisis, to test the shock effect of the financial crisis on all regions. Current research findings at home and abroad show that the financial contagion channel is the main contagion channel for this European Debt Crisis [3] [5] and [23]. Therefore, this paper supposes

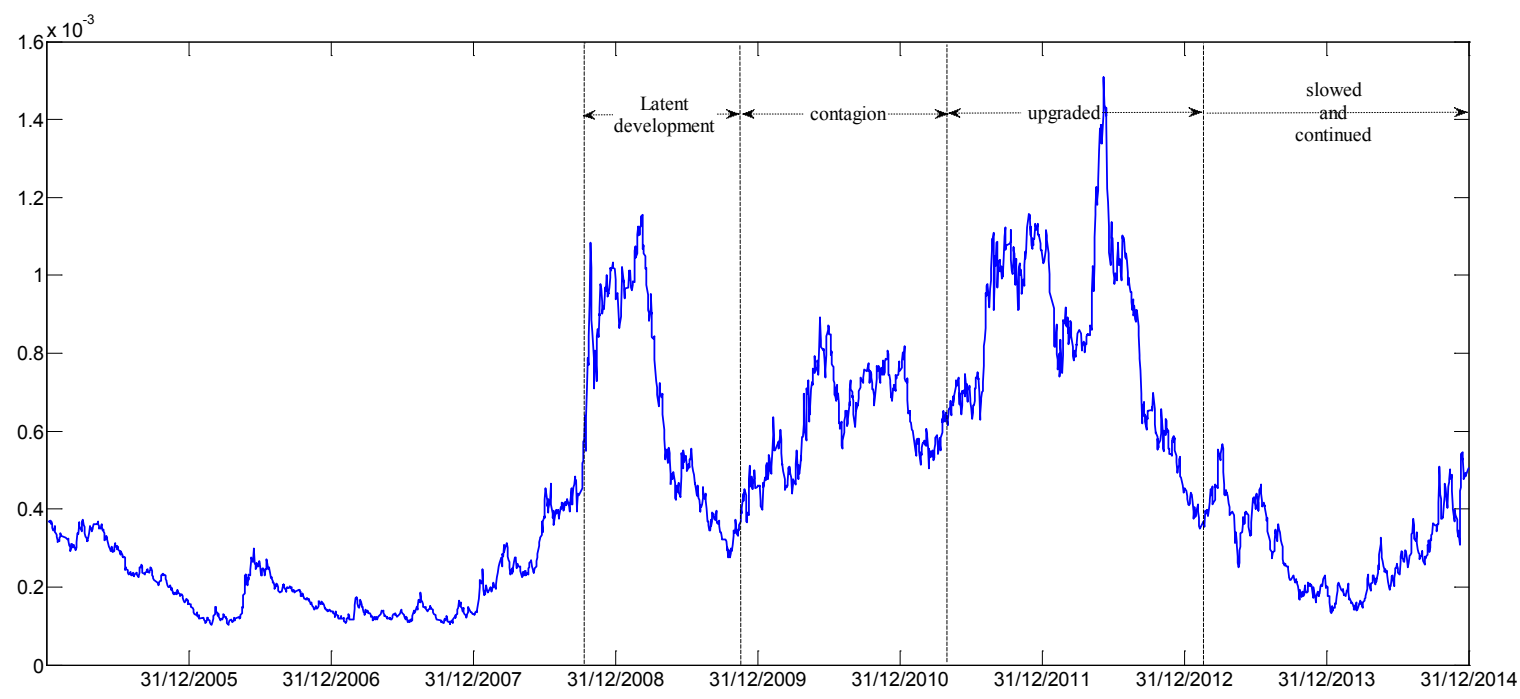

Figure 2. Greek stock indexAR(1)-FIAPARCH $(1, d, 1)$ fluctuation diagram. 
that the financial sector is the contagion medium of the European Crisis on other regions, and according to the financial contagion test process proposed by Baur (2012) [14], Kenourgios and Dimitriou (2015) [15] we mainly test the following two contagion channels: 1) the impact effect of the general stock index yield of the financial crisis source-Greece on other regions-Europe, USA and China; 2) the impact of the financial sector in various regions on other real economy sectors.

With the multivariate Spatial-FIAPARCH-DCC model built in Section 2.2, we test the impact effect of the European Debt Crisis on different regions and different real economy sectors. To test the contagion of the European Financial Crisis, we focus on the two stages of financial crisis spreading and upgrading, i.e. we make the sample interval from December 8, 2009 to January 10, 2013, as the financial crisis period, and other time intervals are defined as the period of financial stability. Figure 3 indicates the AR (1)-FIAPARCH $(1, d, 1)$ punctuations of the financial sector in the crisis source of Greece, and Europe, America and China during the financial crisis period. Table 2 and Table 3 refer to the stock index of Greece-the financial crisis source and the average correlation value of the multivariate Spatial-FIAPARCH-DCC of other economies during the financial crisis and the stability periods respectively. If the average value during the financial crisis is bigger than the average value during stability, we believe that there is contagion effect of the financial crisis on the financial market and real economy [14].

Figure 3 shows that during the European Debt Crisis, the financial markets in Europe and USA had the same abnormal volatilitys to that of the crisis source (Greece); according to Table 2, the multi-variate Spatial-FIAPARCH-DCC averages of the three regions to the European Debt Crisis source of Greece increased, which indicated that during the European Crisis the financial markets of Europe, USA and China were affected during the European Sovereign Debt Crisis, and in terms of value, Europe was under the severe impact, with the European regions under the biggest impact, while China saw the smallest impact.

The findings in Table 3 shows that: 1) The materials, telecommunications, science and technology and energy sectors around the three regions were affected by the European debt crisis, while the health care and consumer goods were under little impact, and here we could not even find any evidence to indicate the impact upon them. 2) In contrast to the impact of the financial market, there are 7 sectors of the real economy of China affected, and the real economy was more widely affected, while the real economy of the most developed USA was affected the least, which indicates that the emerging economy is more fragile, and more susceptible to the financial crisis, and the real economy of the more developed regions become more immune to the financial crisis. This is in line with the findings by Baur (2012), and Baur, and while researching into the impact of the subprime crisis on the real economy, Baur has found that the new emerging Asia and Latin America, relative to the developed regions, were more severely affected by the financial crisis. 


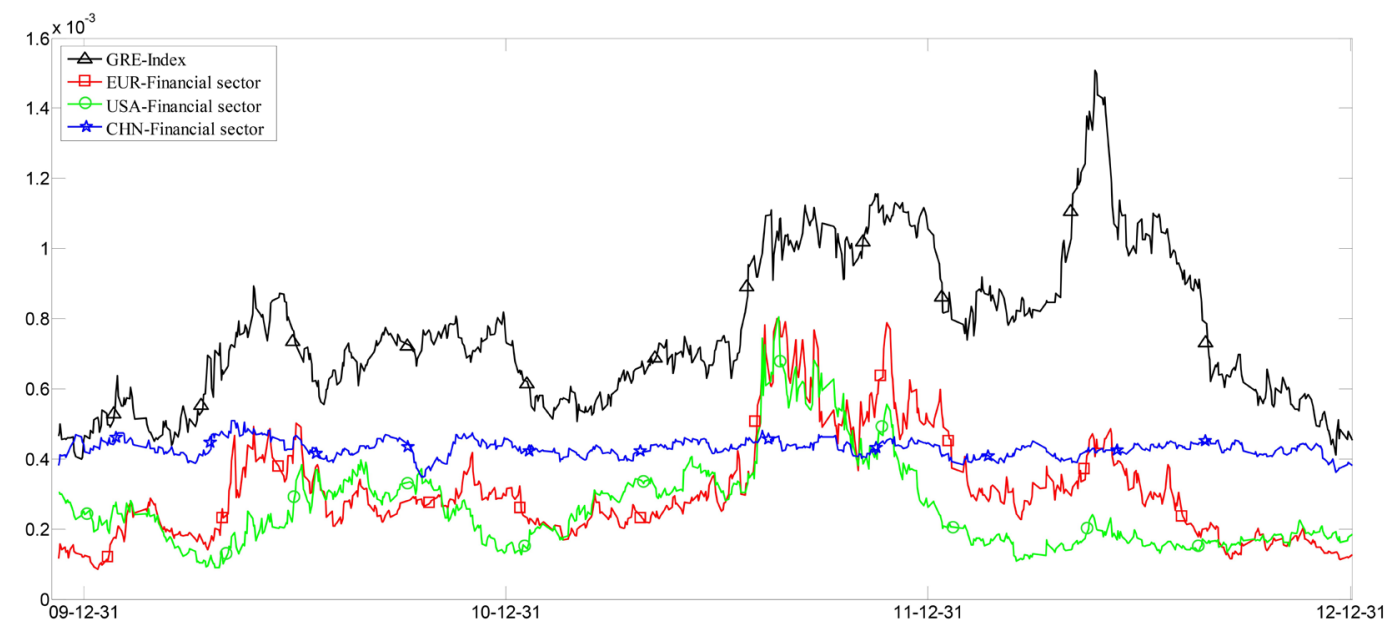

Figure 3. AR(1)-FIAPARCH $(1, d, 1)$ fluctuation diagram of stock index.

Table 2. The Spatial-FIAPARCH-DCC value of the financial crisis source (Greece) on other regional financial sectors.

\begin{tabular}{cccc}
\hline & Europe & United States & China \\
\hline During stability & 0.5403 & 0.1615 & 0.1481 \\
During crisis & 0.6137 & 0.1948 & 0.1590 \\
Contagion & $\mathrm{C}$ & $\mathrm{C}$ & $\mathrm{C}$ \\
\hline
\end{tabular}

Table 3. The contagion of financial industry to local real economy.

\begin{tabular}{|c|c|c|c|c|c|c|c|c|c|}
\hline \multicolumn{10}{|c|}{ Europe: } \\
\hline & Material & $\begin{array}{l}\text { Telecom } \\
\text { munication }\end{array}$ & Industry & $\begin{array}{l}\text { Public } \\
\text { utility }\end{array}$ & $\begin{array}{l}\text { Science and } \\
\text { technology }\end{array}$ & Energy & $\begin{array}{l}\text { Consumer } \\
\text { service }\end{array}$ & $\begin{array}{l}\text { Consumer } \\
\text { goods }\end{array}$ & $\begin{array}{c}\text { Health } \\
\text { care }\end{array}$ \\
\hline Stable period & 0.7442 & 0.6958 & 0.8321 & 0.7068 & 0.7265 & 0.6471 & 0.8227 & 0.7594 & 0.5626 \\
\hline Crisis period & 0.7689 & 0.7047 & 0.8589 & 0.7290 & 0.7299 & 0.6975 & 0.8086 & 0.7383 & 0.5348 \\
\hline Infection & $\mathrm{C}$ & $\mathrm{C}$ & $\mathrm{C}$ & $\mathrm{C}$ & $\mathrm{C}$ & C & & & \\
\hline \multicolumn{10}{|c|}{ U.S.: } \\
\hline Stable period & 0.7223 & 0.6982 & 0.8673 & 0.6602 & 0.7666 & 0.5772 & 0.8477 & 0.8166 & 0.7477 \\
\hline Crisis period & 0.7390 & 0.7083 & 0.8634 & 0.6562 & 0.7675 & 0.6465 & 0.8342 & 0.7973 & 0.7309 \\
\hline Infection & C & $\mathrm{C}$ & & & $\mathrm{C}$ & C & & & \\
\hline \multicolumn{10}{|c|}{ China: } \\
\hline Stable period & 0.7471 & 0.6019 & 0.7608 & 0.7022 & 0.6029 & 0.7313 & 0.7214 & 0.7081 & 0.5817 \\
\hline Crisis period & 0.7655 & 0.6064 & 0.7734 & 0.7134 & 0.6177 & 0.7528 & 0.7471 & 0.7075 & 0.5525 \\
\hline Infection & $\mathrm{C}$ & $\mathrm{C}$ & $\mathrm{C}$ & $\mathrm{C}$ & $\mathrm{C}$ & $\mathrm{C}$ & $\mathrm{C}$ & & \\
\hline
\end{tabular}

\subsection{Spatial Effect Analysis and Financial Contagion Measurement}

In this section, we make use of the spatial SUR model (Equation (10)), to have empirical analysis of the impact of the European Debt Crisis on different regions and different real economy sectors. Time intervals during the financial crisis are the same to the previous section, i.e. the sampled interval from December 8, 
2009 to January 10, 2013, is the duration of the financial crisis, with the virtual variable of $D_{t}=1$; and other sampled time intervals are within the period of financial stability, corresponding to $D_{t}=0$. Here, we have built 4 spatial SUR models to respectively test the spatial effect and the impact of the European Crisis on Europe, America and China, and their real economy sectors.

Table 4 shows the spatial SUR metric results of the spatial effect and the impact of the crisis source-Greece on the financial markets of the three regions of Europe, America, and China, and the interpreting variable $R_{F I N, m, t}$ refers to the volatility sequence of the Greek stock index log yield, the volatility sequence of stock index log yield of the financial sector around the three regions, all items in the model have passed the inspection of significance, which means that our estimation results are reliable. When the $\beta_{2}$ value is bigger than 0 , and has passed the significance inspection, it is defined as the impact of the financial crisis on the corresponding financial market. Analyzing the estimation results of the model, we have found: 1) all the spatial correlation coefficients $\rho$ are more than 0 , and have passed the significance tests, which indicates that the impact of the financial crisis on the three regions show the spatial effect, and there is some homogeneity for the financial market or investors around the three different regions on the financial crisis, and the spatial effect of the Chinese financial market contagion is the smallest. 2) Analyzing the impact effect during the stability and crisis periods, we find all the factors during the crisis period $\beta_{2}$ are more than 0 , and have passed the significance test, which shows that all of the financial markets around the three regions could not avoid the impact, and the European Markets saw the most severe impact, which is in line with the facts; the factor of the Chinese financial market during the stability period did not pass the significance test, which indicates that during stability, the Chinese financial market and the financial crisis source do not have remarkable correlation, and the financial crisis has made the correlation between the two regions remarkably stronger.

Tables 5-7 respectively refer to the SUR measuring results of the spatial effect and the impact of the financial sector in Europe, America and China's on the real economy sectors. Here, we still suppose this financial contagion mainly focuses on the financial channel, respectively making the stock index log yield volatility sequence of the 9 sectors (exclusive of the financial sector) of the real economy in the three regions as the substitutes of the explaining variable $R_{F I N, m, t}$, and the explained variable is the volatility sequence of the financial sector stock log yield across the three regions.

The model evaluation shows that all the adjusted $R^{2}$ are 0.8 , and the $\mathrm{F}$ inspection and D.W. values have passed the statistics inspection, demonstrating that the empirical findings are reliable. Here, we define that when $\beta_{2}$ is more than 0 and has passed the significance inspection, which means that the financial sector in different regions has impact on the real economy. The empirical study results show: 1) all the spatial effect coefficients $\rho$ are more than 0 , which indicates that there is remarkable spatial correlation between the financial market and the 
Table 4. The spatial SUR measurement of the financial crisis on the financial markets in the three regions.

\begin{tabular}{ccccc}
\hline & $\rho$ & $\beta_{1}$ & $\beta_{2}$ & Contagion \\
\hline EUR & $0.6012^{* * *}$ & $0.1179^{* * *}$ & $0.1907^{* * *}$ & $\mathrm{C}$ \\
USA & $0.5403^{* * *}$ & $0.0648^{* * *}$ & $0.0603^{* *}$ & $\mathrm{C}$ \\
CHN & $0.3281^{* * *}$ & -0.0032 & $0.0571^{* * *}$ & $\mathrm{C}$ \\
Adj $R^{2}$ & \multicolumn{2}{c}{0.9028} \\
F-statistic & \multicolumn{2}{c}{$5751.803^{* * *}$} \\
D.W & \multicolumn{2}{c}{2.1217} \\
\hline
\end{tabular}

Note: ${ }^{* *},{ }^{* *}$ and ${ }^{*}$ respectively refer to the tests passing $1 \%, 5 \%$ and $10 \%$ significance levels.

Table 5. The spatial SUR measurement of the financial crisis on real economy in Europe.

\begin{tabular}{|c|c|c|c|c|}
\hline & $\rho$ & $\beta_{1}$ & $\beta_{2}$ & Contagion \\
\hline Materials & $0.2540^{* * *}$ & $0.1959^{* * *}$ & $0.2045^{* * *}$ & $\mathrm{C}$ \\
\hline Telecommunications & $0.1779^{* * *}$ & 0.0048 & $-0.0671^{\star * *}$ & \\
\hline Industries & $0.1622^{\star * *}$ & $0.1691^{\star * *}$ & $0.1135^{\star * *}$ & $\mathrm{C}$ \\
\hline Utilities & $0.2008^{\star * *}$ & $0.1886^{* * *}$ & $0.1181^{\star * *}$ & $\mathrm{C}$ \\
\hline Science and technology & $0.2142^{\star * *}$ & -0.0061 & $-0.0550^{* * *}$ & \\
\hline Energy & $0.2515^{\star * *}$ & $0.2015^{\star *}$ & $0.2907^{\star * *}$ & $\mathrm{C}$ \\
\hline Consumer services & $0.1361^{\star * *}$ & $0.1361^{\star * *}$ & $0.1871^{\star * *}$ & $\mathrm{C}$ \\
\hline Consumer goods & $0.1592^{* * *}$ & $-0.0027^{\star * *}$ & $-0.1240^{* * *}$ & \\
\hline Medical and health care & $0.1840^{* * *}$ & $-0.1646^{* * *}$ & 0.0768 & \\
\hline $\operatorname{Adj} R^{2}$ & \multicolumn{4}{|c|}{0.8182} \\
\hline F-statistic & \multicolumn{4}{|c|}{$2627.286^{* * *}$} \\
\hline D.W & \multicolumn{4}{|c|}{1.9576} \\
\hline
\end{tabular}

Note: ${ }^{* * *},{ }^{* *}$ and ${ }^{*}$ respectively refer to the tests passing $1 \%, 5 \%$ and $10 \%$ significance levels.

Table 6. The spatial SUR measurement of the financial crisis on real economy in the USA.

\begin{tabular}{|c|c|c|c|c|}
\hline & $\rho$ & $\beta_{1}$ & $\beta_{2}$ & Contagion \\
\hline Materials & $0.2580^{* * *}$ & 0.1476 & $0.2747^{\star \star *}$ & $\mathrm{C}$ \\
\hline Telecommunications & $0.1737^{\star * \star}$ & 0.0103 & $0.0391^{\star * *}$ & $\mathrm{C}$ \\
\hline Industries & $0.1495^{\star * *}$ & $0.1389^{\star * *}$ & $-0.0373^{* * *}$ & \\
\hline Utilities & $0.1894^{\star * *}$ & $-0.1153^{\star * *}$ & $-0.0316^{\star *}$ & \\
\hline Science and technology & $0.1785^{\star * *}$ & $0.0295^{\star}$ & $-0.0367^{\star * *}$ & \\
\hline Energy & $0.3028^{\star * *}$ & $0.2691^{\star * *}$ & $0.4653^{* * *}$ & $\mathrm{C}$ \\
\hline Consumer services & $0.1378^{* * *}$ & $0.2272^{* * *}$ & $-0.1671^{\star * \star}$ & \\
\hline Consumer goods & $0.1348^{\star * *}$ & $0.0673^{\star * *}$ & 0.0345 & \\
\hline Medical and health care & $0.1547^{* * *}$ & $0.0016^{* * *}$ & $-0.0628^{\star * \star}$ & \\
\hline $\operatorname{Adj} R^{2}$ & \multicolumn{4}{|c|}{0.8334} \\
\hline F-statistic & \multicolumn{4}{|c|}{$2920.547^{\star * *}$} \\
\hline D.W & \multicolumn{4}{|c|}{1.9820} \\
\hline
\end{tabular}

Note: ${ }^{* *},{ }^{* *}$ and ${ }^{*}$ respectively refer to the tests passing $1 \%, 5 \%$ and $10 \%$ significance levels. 
Table 7. The spatial SUR measurement of the financial crisis on real economy in China.

\begin{tabular}{ccccc}
\hline & $\rho$ & $\beta_{1}$ & $\beta_{2}$ & Contagion \\
\hline Materials & $0.1736^{* * *}$ & -0.0059 & $0.1477^{* * *}$ & $\mathrm{C}$ \\
Telecommunications & $0.2014^{* * *}$ & 0.0122 & $0.0690^{* * *}$ & $\mathrm{C}$ \\
Industries & $0.1598^{* * *}$ & $0.0214^{* *}$ & $0.1234^{* * *}$ & $\mathrm{C}$ \\
Utilities & $0.1587^{* * *}$ & $0.0125^{* * *}$ & $-0.0904^{* * *}$ & \\
Science and technology & $0.2154^{* * *}$ & $-0.2292^{* * *}$ & $0.0354^{* *}$ & $\mathrm{C}$ \\
Energy & $0.1421^{* * *}$ & $0.1226^{* * *}$ & $0.0781^{* * *}$ & $\mathrm{C}$ \\
Consumer services & $0.1635^{* * *}$ & $0.0057^{* * *}$ & $0.0311^{*}$ & $\mathrm{C}$ \\
Consumer goods & $0.1694^{* * *}$ & $-0.0554^{* *}$ & -0.0034 & \\
Medical and health care & $0.1915^{* * *}$ & $-0.1669^{* * *}$ & $-0.1031^{* * *}$ & \\
Adj $R^{2}$ & & \multicolumn{2}{c}{0.8283} & \\
F-statistic & \multicolumn{2}{c}{1.8609} \\
D.W & & \multicolumn{2}{c}{} \\
\hline
\end{tabular}

Note: ${ }^{* *},{ }^{* *}$ and ${ }^{\star}$ respectively refer to the tests passing $1 \%, 5 \%$ and $10 \%$ significance levels.

real economy, so we built the broad multivariate economic space, and built the spatial SUR to analyze the feasibility and necessity for spatial SUR analysis of the financial crisis contagion effect. 2) Altogether there were 14 sectors of the real economy around the three regions affected by the European Debt Crisis, with $51.85 \%$ contagion probability; the materials and energy sectors in the three regions were impacted; the communications, industry and consumer services in two regions were affected; the utilities and science and technology in only one region are affected, while the consumer goods and the medical care sectors around the three regions have not been affected at all. Therefore, during this European Debt Crisis, the impact bears remarkable sectoral agglomeration and hierarchy. First, the impacted real economy includes the materials, energy, industry and communications sectors, while the health and medical care sector basically stay immune to this crisis. 3) The real economies in Europe, America and China saw 5, 3 and 6 sectors under the impact, and the American real economy saw the narrowest impact, and the impact of the European Debt Crisis on China is the widest, while Table 5 tells us the Chinese financial market sees the smallest impact. Therefore, during this European Crisis, the impact on the financial market and the impact range on the real economy are of asymmetry, the more developed region sees stronger resistance of its real economy against the impact, and the emerging markets' real economies are more vulnerable to the impact of the financial crisis.

\section{Conclusions}

This paper defines the broad economic measurement distance and Gravitational effects Spatial Weights Matrix to construct broad multi-dimensional economic space, in which we build diversified Spatial-FIAPARCH-DCC models and Spa- 
tial SUR contagion models using the spatial econometrics, to explore the impact of the different stages of the European Debt Crisis on different regions and different real economy sectors through the contagion channels of the financial market. Further analysis and generalization of the empirical study results helps to make the following conclusions.

1) There is significant spatial effect across different regions, financial markets and the real economies on the globe and the impact financial market on real economy also have remarkable spatial effect. The financial crisis enhanced the spatial correlation of the impact path.

2) The European Debt Crisis has impact on the financial markets in Europe, America and China. But its impact on real economy has remarkable sectoral agglomeration and hierarchy, that is to say, the impacted real economy includes the materials, energy, industry and communications sectors, while the health and medical care sector basically stay immune to this crisis.

3) There is asymmetric relation between the extent to which the real economy suffers and the degree to which the financial market suffers. For example, among the three economies, China had the smallest impact on its financial market but the most affected sectors in its real economy. It saw the smallest impact by the financial crisis probably due to the less openness of the financial market. However, as a major exporter and manufacturer, China is vulnerable to the financial crisis in its real economy sectors. The more financially developed region has the stronger resistance of its real economy against the impact, and the emerging markets' real economies are more vulnerable to the impact of the financial crisis.

4) This paper defines the broad economic metric distance and Gravitational effects Spatial Weights Matrix to construct broad multi-dimensional economic space, as is conducive to matching the financial market theory to the real economy, which provides theoretical reference for us to study the financial market and the real economy's cross-market risks contagion and so on, and avoids aggravating virtualization in the financial sector.

The financial sector now faces more and more serious virtualization, and among the financial reform strategies and academic research, the researches on matching financial market development with the real economy development have just started. In this paper, we have built broad multi-dimensional economic space, and investigated the impact of the financial market on the real economy with the spatial econometrics, which shows high adaptability and validity. Along with the development of the spatial statistics and the spatial econometrics, further research efforts could be made.

\section{Conflicts of Interest}

The authors declare no conflicts of interest regarding the publication of this paper.

\section{References}

[1] Moser, T. (2003) What Is International Financial Contagion? International Finance, 
6, 157-178. https://doi.org/10.1111/1468-2362.00113

[2] Rodriguez, J.C. (2007) Measuring Financial Contagion: A Copula Approach. Journal of Empirical Finance, 14, 401-423. https://doi.org/10.1016/j.jempfin.2006.07.002

[3] Cheng, K., Lu, F. and Yang, X. (2012) Copula Contagion Index and Its Efficiency. Applied Financial Economics, 22, 989-1002. https://doi.org/10.1080/09603107.2011.633889

[4] Asgharian, H. and Nossman, M. (2011) Risk Contagion among International Stock Markets. Journal of International Money and Finance, 30, 22-38. https://doi.org/10.2139/ssrn.1099895

[5] Chudik, A. and Fratzscher, M. (2012) Liquidity, Risk and the Global Transmission of the 2007-08 Financial Crisis and the 2010-11 Sovereign Debt Crisis. European Economic Review. https://doi.org/10.2139/ssrn.2023452

[6] Tian, Y.X., Lu, L.C. and Li, C.G. (2013) Impact of Sovereign Credit Rating Changes on Stock, Bond and Credit Markets. Investment Research, 4, 72-80.

[7] Oh, F.D. (2013) Contagion of a Liquidity Crisis between Two Firms. Journal of Financial Economics, 107, 386-400. https://doi.org/10.1016/j.jfineco.2012.08.018

[8] McKibbin, R.F., Martin, V.L. and Tang, C. (2014) Financial Contagion and Asset Pricing. Journal of Banking and Finance, 47, 296-308. https://doi.org/10.2139/ssrn.2319168

[9] Cavaglia, S., Brightman, C. and Aked, M. (2000) The Increasing Importance of Industry Factors. Financial Analysts Journal, 56, 41-54.

http://www.jstor.org/stable/4480272

[10] Phylaktis, K. and Xia, L. (2006) Sources of Firms' Industry and Country Effects in Emerging Markets. Journal of International Money and Finance, 25, 459-475. https://doi.org/10.1016/j.jimonfin.2006.02.001

[11] Phylaktis, K. and Xia, L. (2009) Equity Market Comovement and Contagion: A Sectoral Perspective. Financial Management, 38, 381-409. https://doi.org/10.1111/j.1755-053X.2009.01040.x

[12] Horta, P., Mendes, C. and Vieira, I. (2010) Contagion Effects of the Subprime Crisis in the European NYSE Euronext Markets. Portuguese Economic Journal, 9, 115-140. https://doi.org/10.1007/s10258-010-0056-6

[13] Bekaert, G., Ehrmann, M., Fratzscher, M. and Mehl, A. (2011) Global Crises and Equity Market Contagion. Journal of Finance, 42, 551-574. https://doi.org/10.3386/w17121

[14] Baur, D.G. (2012) Financial Contagion and the Real Economy. Journal of Banking and Finance, 36, 2680-2692. https://doi.org/10.1016/j.jbankfin.2011.05.019

[15] Kenourgios, D. and Dimitriou, D. (2015) Contagion of the Global Financial Crisis and the Real Economy: A Regional Analysis. Economic Modelling, 44, 283-293. https://doi.org/10.1016/j.econmod.2014.10.048

[16] Elhorst, P. and Vega, S.H. (2013) On Spatial Econometric Models, Spillover Effects, and W. European Regional Science Association.

[17] Fingleton, B. (2003) Externalities, Economic Geography, and Spatial Econometrics: Conceptual and Modelling Developments. International Regional Science Review, 207, 197-207. https://doi.org/10.1177/0160017602250976

[18] Tita, G.E. and Radil, S.M. (2010) Spatial Regression Models in Criminology: Modeling Social Processes in the Spatial Weights Matrix. In: Handbook of Quantitative Criminology, Springer, New York, 101-121. 
https://doi.org/10.1007/978-0-387-77650-7_6

[19] Brown, J.P., Lambert, D.M. and Florax, R.J.G.M. (2013) The Birth, Death, and Persistence of Firms: Creative Destruction and the Spatial Distribution of US Manufacturing Establishments, 2000-2006. Economic Geography, 89, 203-226. https://doi.org/10.1111/ecge.12014

[20] Zhang, J.W., Chen, X. and Wang, S.Y. (2009) New Spatial Weight Matrix and Its Application in China's Regional Foreign Trade. Systems Engineering: Theory and Practice, 29, 84-92.

[21] Kelejian, H.H., Tavlas, G.S. and Hondroyiannis, G. (2006) A Spatial Modelling Approach to Contagion among Emerging Economies. Open Economies Review, 17, 423-441. https://doi.org/10.1007/s11079-006-0357-7

[22] Inci, A., Li, H.C. and McCarthy, J. (2011) Financial Contagion: A Local Correlation Analysis. Research in International Business and Finance, 25, 11-25. https://doi.org/10.1016/j.ribaf.2010.05.002

[23] Cheng, K., Lu, F.B. and Yang, X.G. (2012) Spatial Analysis of US Subprime Mortgage Crisis Contagion. Systems Engineering: Theory and Practice, 32, 483-494.

[24] Eckel, S., Löffler, G., Maurer, A. and Schmidt, V. (2011) Measuring the Effects of Geographical Distance on Stock Market Correlation. Journal of Empirical Finance, 18, 237-247. https://doi.org/10.1016/j.jempfin.2010.12.001

[25] Dell'Erba, S., Baldacci, E. and Poghosyan, T. (2013) Spatial Spillovers in Emerging Market Spreads. Empirical Economics, 45, 735-756.

https://doi.org/10.1007/s00181-012-0644-7

[26] Tam, P.S. (2014) A Spatial-Temporal Analysis of East Asian Equity Market Linkages. Journal of Comparative Economics, 42, 304-327.

https://doi.org/10.1016/j.jce.2014.03.008

[27] Arnold, M., Stahlberg, S. and Wied, D. (2011) Modelling Different Kinds of Spatial Dependence in Stock Returns. Empirical Economics, 44, 761-774. https://doi.org/10.1007/s00181-011-0528-2

[28] Pirinsky, C. and Wang, Q. (2006) Does Corporate Headquarters Location Matter for Stock Returns? The Journal of Finance, 61, 1991-2015. https://doi.org/10.2139/ssrn.733483

[29] Fernandez, V. (2011) Spatial Linkages in International Financial Markets. Quantitative Finance, 11, 237-245. https://doi.org/10.1080/14697680903127403

[30] Mantegna, R.N., Stanley, H.E. and Chriss, N.A. (2000) Introduction to Econophysics: Correlations and Complexity in Finance. Cambridge University Press, Cambridge. https://doi.org/10.1063/1.1341926

[31] Liu, K., Daly, K. and Varua, M.E. (2012) Determinants of Regional Distribution of FDI Inflows across China's Four Regions. International Business Research, 5, 119. https://doi.org/10.5539/ibr.v5n12p119

[32] Tse, Y.K. and Tsui, A.K.C. (2002) A Multivariate Generalized Autoregressive Conditional Heteroscedasticity Model with Time-Varying Correlations. Journal of Business and Economic Statistics, 20, 351-362. https://doi.org/10.1198/073500102288618496

[33] Forbes, K.J. and Rigobon, R. (2002) No Contagion, Only Interdependence: Measuring Stock Market Comovements. The Journal of Finance, 57, 2223-2261. https://doi.org/10.1111/0022-1082.00494

[34] Conrad, C., Karanasos, M. and Zeng, N. (2011) Multivariate Fractionally Integrated APARCH Modelling of Stock Market Volatility: A Multi-Country Study. Journal of 
Empirical Finance, 18, 147-159. https://doi.org/10.1016/j.jempfin.2010.05.001

[35] Bekaert, G., Harvey, C.R. and Ng, A. (2005) Market Integration and Contagion. Journal of Business, 78, 39-70. https://doi.org/10.1086/426519 